\title{
Enfermedad del suero secundaria al uso de rituximab en pacientes con síndrome de Sjögren primario
}

\author{
Lina Maria Saldarriaga Rivera', César Ricardo Ortega Espinosa ${ }^{2}$, Luis Alberto Delgado Quiroz ${ }^{1}$ \\ ${ }^{1}$ Servicio de Reumatología del Hospital Universitario Clementino Fraga Filho. Universidad Federal de Río de Janeiro-Brasil. \\ ${ }^{2}$ Hospital Universitario Antonio Pedro, Río de Janeiro-Brasil.
}

\begin{abstract}
Resumen
La enfermedad del suero constituye un síndrome clínico causado por la formación de complejos inmunes que generan una reacción de hipersensibilidad, con manifestaciones clínicas típicas de erupción cutánea, artritis, y fiebre que inician de 1 a 3 semanas después de la administración de un fármaco y suelen desaparecer al cabo de varios días de interrumpir la administración del agente causal, pudiendo persistir durante intervalos mayores, especialmente cuando son fármacos de acción prolongada o retardada. Se describe el caso de una paciente con síndrome de Sjögren primario que presentó enfermedad del suero secundaria al uso de rituximab.
\end{abstract}

Palabras clave: enfermedad del suero, síndrome de Sjögren, rituximab.

\section{Summary}

Serum sickness is a clinical syndrome caused by the formation of immune complexes that generate a hypersensitivity reaction. Typical manifestations are rashes, arthritis, and fever beginning within 3 weeks after administration of a drug and usually disappear several days after the suppression of the causative agent, although they might persist for longer periods, especially with long-acting drugs. We describe the case of a female patient with primary Sjogren's syndrome who presented secondary serum sickness after using rituximab.

Key words: serum sickness, Sjögren's syndrome, rituximab.

\section{Introducción}

La enfermedad del suero se describe como una reacción de hipersensibilidad generalmente a fármacos, mediada por depósitos de complejos inmunes circulantes en pequeños vasos sanguíneos, la cual induce la activación del complemento y subsecuente inflamación ${ }^{1}$.

Los síntomas y signos más frecuentes son fiebre, erupción cutánea (morbiliforme, urticariana o ambas), artralgias, nefritis, neuropatía y vasculitis. En casos severos puede aparecer glomerulonefritis e hipertensión arterial, e incluso fiebre y adenopatías ${ }^{2}$.

El diagnóstico se realiza según la sintomatología, aunque algunos hallazgos de laboratorio sirven para su confirmación, como los valores del complemento que pueden estar reducidos, y la velocidad de sedimentación globular elevada. El hemograma muestra frecuentemente neutropenia, trombocitopenia y eosinofilia que puede estar presente, pero no es relevante ${ }^{3}$.

Durante la enfermedad del suero, el análisis de orina demuestra la proteinuria leve en aproximadamente la mitad de los pacientes; aquellos con proteinuria también pueden desarrollar hematuria leve transitoria sin cilindros celulares. Ocasionalmente, la creatinina sérica se eleva hasta aproximadamente dos veces el valor normal, pero la disfunción renal tiende a resolverse en unos pocos días ${ }^{4}$.

El tratamiento es basado en el uso de antihistamínicos, agentes antiinflamatorios no esteroideos $\mathrm{y}$ analgésicos. En pacientes con artritis y erupciones extensas se administra glucocorticoides por vía oral a una dosis de prednisona $0,5-1,0 \mathrm{mg} / \mathrm{kg} /$ día o en casos más graves, se puede considerar el uso de metilprednisolona intravenosa a dosis de $1-2 \mathrm{mg} / \mathrm{kg} / \mathrm{dia}^{5}$.

\section{Correspondencia}


Una vez que la enfermedad del suero es diagnosticada, el fármaco responsable debe evitarse en el futuro ${ }^{6}$.

\section{Caso clínico}

Paciente de 40 años, sexo femenino, blanca, natural de Río de Janeiro, con historia de parotiditis a repetición, inició cuadro de xerostomía, xeroftalmia, alopecia y sequedad de la piel, con aumento de glándula parótida persistente por más de 2 meses.

Al examen físico presentaba edema pre-mandibular izquierdo, xerostomía, sin adenopatías axilares o cervicales, sin alopecia localizada.

Los exámenes de laboratorio demostraban HCTO (hematocrito): 38\%, HB (Hemoglobina): $13 \mathrm{mg} / \mathrm{dl}$, Leucocitos: $7.800 / \mathrm{mm}^{3}$, Plaquetas: $205.000 / \mathrm{mm}^{3}$, VSG (eritrosedimentación): $13 \mathrm{~mm} / \mathrm{h}, \mathrm{PCR}: 0,29 \mathrm{mg} / \mathrm{L}$, TGO: 21U/L, TGP: 14U/L, Urea: $22 \mathrm{mg} / \mathrm{dl}$, Creatinina: 0,9 mg/ dl, ANA: negativo, serología para hepatitis B y C: negativo, Anti-Ro: 1/6400, Anti-La: negativo, C3: $137 \mathrm{mg} / \mathrm{dl}$, C4: $8 \mathrm{mg} / \mathrm{dl}$, TSH: 1,0mUI/l. T4:0,7 mUI/l, Electroforesis de proteínas: hipergammaglobulinemia 23,4\% (2,3 g/ dl), Anti-DNA: negativo, Anti-Sm: negativo, Anti-RNP: negativo.

La paciente fue valorada por oftalmología quien realizó test Schirmer $<1 \mathrm{~mm}$, rosa de bengala: $7, \mathrm{BUT}<10 \mathrm{seg}$.

La gammagrafía de glándula parótida reveló hallazgos compatibles con síndrome de Sjögren. Biopsia de mucosa de labio inferior: síndrome de Sjögren clase III Chisholm y Mason. Tomografía de tórax: normal.

La paciente fue diagnosticada con síndrome de Sjögren primario recibiendo tratamiento con prednisona 10 $\mathrm{mg} /$ día, cloroquina $150 \mathrm{mg}$ /día y colirio oftálmico.

Posterior a los seis meses de tratamiento, la paciente persistía con artritis, parotiditis, y aumento de la sequedad en ojos y boca, con imágenes de infiltrado inflamatorio compatibles con alveolitis en la tomografía de tórax, AntiRo: 1/8000, Anti-La: negativo, Hipergammaglobulinemia policlonal $28 \%$ (2,7 g/dl), VSG (eritrosedimentación) y PCR: normales, por lo que se decide iniciar ciclosporina $100 \mathrm{mg} /$ día, prednisona $20 \mathrm{mg} /$ día.

Después de un año de tratamiento continuo con ciclosporina $150 \mathrm{mg} / \mathrm{d}$ ía, manteniendo niveles séricos adecuados y cuantificados en 2 ocasiones (12 horas posterior a la dosis oral). A pesar de que la paciente no usaba otras medicaciones y no tenía comorbilidades que interfirieran con el metabolismo de la ciclosporina, se consideró fracaso terapéutico, y se decidió cambiar la medicación por biológico Rituximab, presentando una excelente respuesta terapéutica hasta la aplicación de la tercera dosis, donde inicia 1 semana después con cuadro clínico de fiebre de 38,5 grados, mialgias, artralgias, astenia, adinamia y urticaria.

Los exámenes de laboratorio demostraban HCTO (hematocrito): 37\%, HB (Hemoglobina): 12,5 mg/dl, Leucocitos: $7.500 / \mathrm{mm}^{3}$, Plaquetas: $155.000 / \mathrm{mm}^{3}$, VSG (eritrosedimentación): $24 \mathrm{~mm} / \mathrm{h}$, PCR: $3 \mathrm{mg} / \mathrm{L}, \mathrm{TGO}: 29$ U/L, TGP: $71 \mathrm{U} / \mathrm{L}$, Urea: $27 \mathrm{mg} / \mathrm{dl}$, Creatinina: $0,9 \mathrm{mg} /$ dl, Fosfatasa alcalina: $81 \mathrm{U} / \mathrm{L}, \mathrm{C} 3: 150 \mathrm{mg} / \mathrm{dl}, \mathrm{C} 4: 7 \mathrm{mg} /$ dl, electrólitos normales.

La paciente fue tratada con prednisona $30 \mathrm{mg} / \mathrm{día}$ durante 10 días, paracetamol y antihistamínicos, con resolución del cuadro clínico.

\section{Discusión}

La enfermedad del suero es una enfermedad caracterizada por fiebre, erupción cutánea y artralgias que puede ocurrir en pacientes que reciben terapia con anticuerpo monoclonal quimérico y en hasta el 3\% de los casos después de la terapia con anti-TNF alfa'.

Rituximab, un anticuerpo monoclonal quimérico dirigido contra CD20 que se expresa en precursores de células $B$, se ha utilizado con mayor frecuencia en el tratamiento de enfermedades reumatológicas como la artritis reumatoidea, lupus eritematoso sistémico y en las manifestaciones extraglandulares del síndrome de Sjögren ${ }^{8}$.

La mejoría de manifestaciones extraglandulares con el tratamiento de rituximab se informó en un ensayo que incluyó a 30 pacientes con síndrome de Sjögren. Ellos fueron seleccionados al azar para recibir rituximab (20 pacientes) o placebo (10 pacientes). Todos los pacientes recibieron metilprednisolona IV antes de la infusión. Evidenciando una mejora significativa en la secreción salival en los pacientes en el grupo de tratamiento con rituximab y una mejora significativa en la escala analógica visual del grado de sequedad?

En un estudio retrospectivo de seis pacientes tratados con cuatro infusiones de rituximab $\left(375 \mathrm{mg} / \mathrm{m}^{2}\right)$ cada semana, cinco de los seis pacientes tuvieron regresión en el aumento de la glándula parótida y mejora de las artralgias ${ }^{10}$.

Manifestaciones extraglandulares del síndrome de Sjögren, que eran refractarios a al menos dos fármacos inmunosupresores, respondieron favorablemente a rituximab, con un nivel aceptable de toxicidad en pacientes estudiados por un grupo español ${ }^{11}$. 
Otro estudio realizado con 28 pacientes observó una mejoría significativa en las manifestaciones extraglandulares, medida por el ESSDAI (índice de actividad de la enfermedad), a las 60 semanas después del tratamiento con dos dosis de 1 gramo de rituximab ${ }^{12}$.

En el caso clínico relatado, se evidencia cómo la paciente mejoró las manifestaciones clínicas de síndrome de Sjögren, pese a la falla terapéutica presentada con el uso de inmunosupresor y glucocorticoide. El rituximab fue una excelente opción terapéutica hasta el momento en que el medicamento indujo la enfermedad del suero.

\section{Conclusión}

Varias series de casos y un ensayo aleatorio pequeño han puesto de manifiesto el potencial de rituximab como agente terapéutico en el síndrome de Sjögren. Sin embargo, existen reportes donde este tipo de anticuerpo quimérico anti-células B es uno de los agentes causales de la enfermedad del suero.

La enfermedad del suero inducida por el uso de rituximab en un paciente con síndrome de Sjögren primario, es un caso poco descripto en la literatura.

\section{Declaración de fuentes de financiación y posible con- flicto de intereses \\ No hay conflicto de intereses. \\ Fuente de financiación: ninguna.}

\section{Bibliografía}

1. Yerushalmi J, Zvulunov A, Halevy S. Serum sickness-like reactions. Cutis. 2002; 69:395-397.

2. Wolf R, Orion E, Marcos B, Matz H. Life-threatening acute adverse cutaneous drug reactions. Clin Dermatol. 2005; 23:171-181.

3. Lawley TJ, Bielory L, Gascon P, Yancey KB, Young NS, Frank MM. A prospective clinical and immunologic analysis of patients with serum sickness. $\mathrm{N}$ Engl J Med 1984; 311:1407-1413.
4. Erffmeyer JE. Serum sickness. Ann Allergy 1986; 56:105-110.

5. D'Arcy CA, Mannik M. Serum sickness secondary to treatment with the murine-human chimeric antibody IDEC-C2B8 (rituximab). Arthritis Rheum 2001; 44:1717-1718.

6. Todd DJ, Helfgott SM. Serum sickness following treatment with rituximab. J Rheumatol 2007; 34:430-433.

7. Schutgens RE. Rituximab-induced serum sickness. Br J Haematol 2006; 135(2):147-148.

8. Thanou-Stavraki A, James JA. Primary Sjogren's syndrome: current and prospective therapies. Semin Arthritis Rheum 2008; 37:273-292.

9. Meijer JM, Meiners PM, Vissink A, Spijkervet FK, Abdulahad W, Kamminga N, et al. Effectiveness of rituximab treatment in primary Sjögren's syndrome: a randomized, double-blind, placebocontrolled trial. Arthritis Rheum 2010; 62:960-968.

10. Meiners PM, Vissink A, Kallenberg CG, Kroese FG, Bootsma. Treatment of primary Sjögren's syndrome with anti-CD20 therapy (rituximab). A feasible approach or just a starting point? Expert Opin Biol Ther 2011; 11:1381-1394.

11. Ramos-Casals M, García-Hernández FJ, de Ramón E, Callejas JL, Martínez-Berriotxoa A, Pallarés L, et al. Off-label use of rituximab in 196 patients with severe, refractory systemic autoimmune diseases. Clin Exp Rheumatol 2010; 28:468-476.

12. Meiners PM, Arends S, Brouwer E, Spijkervet FK, Vissink A, Bootsma HB. Responsiveness of disease activity indices ESSPRI and ESSDAI in patients with primary Sjögren's syndrome treated with rituximab. Ann Rheum Dis 2012; 71:1297-1302. 